Casos Clínicos

Arch. Esp. Urol., 61, 3 (442-444), 2008

\section{ORQUIEPIDIDIMITIS POR BRUCELLA SPP}

Daniel Gallego Vilar, Ivan Povo Martín, Vicente Gimeno Argente, M. Bosquet, Isabel Rivadulla Serrano, David Martínez Ramos y Juan Gallego Gómez.

Servicio de Urología y Servicio de Cirugía General y Aparato Digestivo. Hospital General de Castellón. Castellón. España.

Resumen.- OBJETIVO: Presentar un caso de orquiepididimitis unilateral por Brucella y realizar una pequeña revisión de diagnóstico y tratamiento de la patología.

MÉTODO: Presentamos a un varón de 62 años que refiere síndrome constitucional, fiebre y dolor testicular, el diagnóstico se basó en la anamnesis, hemocultivos y estudios de imagen ecográfica.

RESULTADOS: El tratamiento se inició con Doxiciclina y Teicoplanina, manteniéndose el primero durante seis semanas y sustituyéndose el segundo por ciprofloxacino (dos semanas en totall) al alta, con resolución completa del cuadro.
CONCLUSIÓN: Se debe ser exhaustivo en la anamnesis del paciente con orquitis infecciosa, ya que ésta puede revelar datos sugerentes de la etiología del cuadro, siendo de especial relevancia en la afectación por Brucella, ya que se presenta en pacientes de riesgo. Sin embargo se antoja necesaria la realización de hemocultivos que revelen Brucella en sangre para confirmar el diagnóstico. Los tratamientos antibióticos orales actuales son más que suficientes para resolver el cuadro. Siendo el tratamiento quirúrgico excepcional hoy en día.

Palabras clave: Brucelosis. Infección. Orquiepididimitis.

Summary.- OBJECTIVE: To report a brucellar orchie-pididymitis case and to review the diagnosis and treatment of this pathology.

METHOD: We present the case of a 62 year old man presenting with fever, testicular pain and constitutional syndrome. The diagnosis was made after ultrasound, blood cultures and anamnesis.

RESULTS: The treatment was Doxiciclin six weeks and teicoplanin, the second one was replaced with ciprofloxacin.

CONCLUSION: It is important to make a correct anamnesis to the patient with orchiepididymitis to identify any risk factor for brucellosis. The diagnosis is confirmed with blood cultures. The oral antibiotics are enough to cure patients.

Keywords: Brucellosis. Infection. Orchiepididymitis.

\title{
INTRODUCCIÓN
}

La brucelosis es una zoonosis causada por pequeñas bacterias, cocobacilos GRAM negativos de la familia Brucella spp. En la actualidad se conocen cuatro géneros dentro de esta familia: Brucella abortus (el huésped definitivo es el cerdo), Brucella canis (huésped definitivo: perro), Brucella Bovis (huésped definitivo: bovinos), Brucella melitensis.

Brucella puede infectar al ser humano y convertirse éste en huésped intermedio de la bacteria, mediante el contacto con animales, sus líquidos biológicos (siendo esta forma de contagio la más frecuente entre población de riesgo como veterinarios, personas que trabajan en mataderos, ganaderos...) o la ingesta-contacto de alimentos derivados de ellos (leche, quesos..., siendo esta forma de contagio la más frecuente entre la población general).

La Brucelosis típicamente se presenta en forma de picos febriles junto con astenia, anorexia, sudoración profusa 
y artralgia debido a que Brucella se acantona en diversos órganos y desde ahí genera crisis bacteriémicas que explican la clínica comentada.

En el transcurso de esas crisis de bacteriemia, el germen puede afectar a diversos tejidos (articular, digestivo...) y de entre ellos al riñón y tracto genitourinario en forma de Nefropatía IgA, GMN exudativa, nefritis intersticial, pielonefritis, absceso renal $y$, siendo la forma de afección genitourinario más frecuente orquiepididimitis (8), infección no limitada y que puede terminar con atrofia del teste (10) y esterilidad (ya que no es infrecuente que sea bilateral), de ahí la importancia de su correcto tratamiento.

\section{DESCRIPCIÓN DEL CASO}

Varón de 62 años de edad, que acude a urgencias por referir dolor testicular izquierdo de 24 horas de evolución, acompañado de fiebre termometrada de $40^{\circ} \mathrm{C}$, junto con escalofríos y síndrome miccional acompañante (disuria, polaquiuria, tenesmo y urgencia miccional), ausencia de dolor lumbar.

Durante la anamnesis el paciente revela su profesión, veterinario, profesión de riesgo para ciertas patologías infecciosas (brucelosis, triquinosis y algunas parasitosis).

A la exploración se objetiva un teste derecho de características normales, y, en el teste izquierdo, se visualiza un aumento de tamaño así como eritema y dolor al tacto sin fluctuación de la zona afecta aunque con dolor a la movilización testicular.

El tacto rectal resulta sin hallazgos patológicos y la exploración abdominal así como la percusión renal también descartó afecciones acompañantes al ser normales.

Analíticamente destaca leucocitosis de 22.240 con neutrofilia (neutrófilos 90\%).

En la Ecografía testicular realizada previa al ingreso muestra aumentos homogéneos de la ecogenicidad del testículo afecto, sin afectación del epidídimo. Engrosamiento de partes blandas con ausencia de absceso testicular. Imágenes compatibles con orquitis sin afectación del epidídimo.

Se realiza el diagnóstico de orquitis infecciosa, procediéndose a su ingreso con un tratamiento antibiótico que comprendió Doxiciclina, Imipenem y Teicoplanina, asociando Corticoides y terapia analgésica.

Dos días tras el ingresse realiza una nueva ecografía, objetivándose aumento de la ecogenicidad homogénea similar al contralateral, afectación epididimaria. Engrosamiento de partes blandas con ausencia de absceso testicular. Se termina de filiar el cuadro sindrómico: Orquiepididimitis infecciosa.

Para averiguar la causa de la patología que presenta el paciente se hace necesaria la realización de pruebas que permitan conocer el germen causante.

El urocultivo resulta ser negativo, así como la aglutinación específica de Brucella. Sin embargo la seroaglutinación de Rosa de Bengala resulta positiva, así como los hemocultivos, que son positivos a Brucella spp. (los tres).

Ante la confirmación del diagnóstico de orquiepididimitis brucelar se decide mantener el tratamiento con Doxiciclina y ciprofloxacino.

El paciente evoluciona favorablemente con remisión completa de los síntomas.

\section{DISCUSIÓN}

Los pacientes infectados por Brucella con afectación orquiepididimaria refieren en el contexto de la clínica típica de la infección por Brucella $(1,2,3,7)$, dolor testicular de inicio súbito irradiado en ocasiones a zona inguinal o incluso lumbar ipsilateral con inflamación y calor local, aumento del tallo epididimario visualizándose el escroto y cordón rojos, tensos, edematosos y calientes a la palpación.

La exploración del teste afecto es similar al de todo proceso inflamatorio infeccioso testiculoepididimario, con palpación muy dolorosa en teste y epidídimo.

Ante un paciente con esta clínica se nos plantea la única duda entre el más que posible proceso infeccioso y una torsión de teste $(6,9)$, pero el primero suele afectar a personas de riesgo y con clínica de sepsis, mientras que la torsión testicular lo hace a gente de menor rango de edades, en ausencia de clínica séptica sistémica y durante la noche. En el caso en el que la clínica y la exploración no resulten suficientes para descartar una afectación distinta a la infección testicular, se puede recurrir a la ECO transescrotal, donde podríamos objetivar, en caso de orquiepididimitis, un engrosamiento de las capas del escroto +/- del epidídimo (sobretodo en región cefálica), así como un aumento del diámetro del teste con hipoecogenicidad. En último caso se puede recurrir a más pruebas de imagen como el modo Dopler en la ecografía, la gammagrafía o incluso la RMN (sobretodo para descartar neoplasias).

Es cierto que existen estudios que se han realizado con el objetivo de intentar averiguar la existencia de diferencias morfológicas o de vascularización entre ecografías testiculares de orquiepididimitis clásicas y las causadas por Brucella, sin embargo los resultados resaltaron la ausencia de diferencias ecográficas. 
Desde el punto de vista clínico la inflamación orquiepididimaria no presenta ningún síntoma ni signo específico respecto al resto de orquiepididimitis, aunque el que los síntomas se presenten en un paciente considerado de riesgo y con afectación séptica larvada generalizada nos orientan hacia la sospecha diagnóstica, por lo tanto el diagnóstico de orquiepididmitis como síndrome clínico no difiere respecto a las orquiepididimitis clásicas (la exploración y la ECO dopler tranescrotal no presentan diferencias) (4) salvo en el urocultivo, sin embargo para este diagnóstico etiológico sí que se requiere de pruebas complementarias que nos permitan tipificar la causa de la inflamación séptica del teste y epidídimo.

El diagnóstico de confirmación pasa por el aislamiento de la bacteria causante del cuadro a nivel sanguíneo, ya que los urocultivos no tienen porqué ser positivos (sólo $1-40 \%$ de los casos) y por lo tanto su rendimiento resulta muy bajo, sin embargo el aislamiento del patógeno en sangre suele ser muy rentable, resultando positivo en más de un $76 \%$ de los casos. Si el hemocultivo no nos diera el diagnóstico de confirmación se puede recurrir a la serología, donde títulos de anticuerpos tipo $\lg G$ específicos de Brucella superiores o iguales a 160 nos confirmarían el diagnóstico etiológico. Estos anticuerpos no sólo nos sirven para el diagnóstico de la enfermedad sino también para seguir la evolución del cuadro, ya que se ha visto que la reducción progresiva de los anticuerpos a nivel sérico se traduce como signo de buen pronostico de enfermedad. Otros datos averiguados a nivel sanguíneo no resultan de gran utilidad, ya que el Hemograma no tiene porqué ser patológico (puede ser normal o incluso presentar citopenia de alguna o todas las series).

En nuestro caso la asociación de orquitis con profesión de riesgo permitió sospechas Brucella como etiología del proceso.

Por lo tanto, pese a ser una patología que actualmente presenta un baja endemia en el mundo desarrollado, debemos de tener en cuenta la orquiepididimitis por Brucella ante un cuadro de inflamación séptica del teste +/- epidídimo, sobretodo si durante la anamnesis el paciente se puede encuadrar el grupos de riesgo (profesiones e ingesta de alimentos de riesgol y refiere clínica sistémica que nos haga sospechar la existencia de bacteriemias transitorias (astenia, anorexia, sudoración fétida, pérdida de peso, adenopatías y hepatoesplenomegalia).

El diagnóstico sindrómico no difiere del resto de orquiepididimitis salvo por el echo de que los urocultivos suelen tener un muy bajo rendimiento, siendo la exploración, clínica local y la ECO transescrotal similares a las orquiepididimitis clásicas.De modo que hemos de recurrir al aislamiento del germen responsable a nivel sérico, teniendo en el hemocultivo la principal herramienta de diagnóstico etiológico del cuadro.

\section{CONCLUSIÓN}

El tratamiento antibiótico ha sufrido ligeros cambios en estos últimos años respecto a la clásica terapia consistente en Doxiciclina junto con la estreptomicina, para ser sustituido por tratamientos de mejor tolerancia, igual efectividad y gran espectro como la asociación Doxiciclina junto con rifampicina o quinolonas vía oral durante periodos prolongados. Se ha objetivado en las últimas series que la administración oral de estos antibióticos resulta de igual eficacia y reduce el coste ya que exime al paciente de una estancia hospitalaria prolongada. Por supuesto el tratamiento antibiótico se debe acompañar de terapia para los síntomas como antipiréticos, analgesia, fluidoterapia, reposo, frío local y suspensorio, siendo los resultados de la terapia muy aceptables en general.

\section{BIBLIOGRAFIA y LECTURAS RECOMENDADAS (*lectura de interés $y$ ** lectura fundamental)}

*1. AL-TAWFIQ, J.A.; AKINCI, E.; BODUR, H. y cols.: "Brucella epididymo-orchitis: A consideration in endemic area". Int. Braz. J. Urol., 32: 313, 2006.

**2. LOPEZ RODRÍGUEZ, R.; ARIAS RIVAS, S.; GONZALEZ BÁRBARO, E. y cols.: "Brucella epididymoorchitis". An. Med. Interna, 22: 400, 2005.

**3. PEREZ FENTES, D.; BLANCO PARRA, M.; ALENDE SIXTO, M. y cols.: "Brucella orchyoepididymitis: Case report”. Arch. Esp. Urol., 58: 674, 2005.

**4. OZTURK, A.; OZTURK, E.; ZEYREK, F. y cols.: "Comparison of brucella and non-specific epididymorchitis: Gray scale and color Doppler ultrasonographic features". Eur. J. Radiol., 56: 256, 2005.

*5. YETKIN, M.A.; ERDINC, F.S.; BULUT, C. y cols.: "Epididymoorchitis due to brucellosis in central Anatolia, Turkey". Urol. Int., 75: 235, 2005.

*6. ALAPONT ALACREU, J.M.; GOMEZ LOPEZ, L.; DELGADO, F. y cols.: "Brucellar orchiepididymitis". Actas Urol. Esp., 28: 774. 2004.

**7. HASANJANI ROUSHAN, M.R.; MOHREZ, M.; SMAILNEJAD GANGI, S.M. y cols.: "Epidemiological features and clinical manifestations in 469 adult patients with brucellosis in Babol, Northern Iran". Epidemiol. Infect., 132: 1109, 2004.

**8. HATIPOGLU, C.A.; YETKIN, A.; ERTEM, G.T. y cols.: "Unusual clinical presentations of brucellosis". Scand. J. Infect. Dis., 36: 694, 2004.

**9. HATIPOGLU, C.A.; YETKIN, A.; ERTEM, G.T. y cols.: "Unusual clinical presentations of brucellosis". Scand. J. Infect. Dis., 37: 784, 2005.

*10. KOCAK, I.; DUNDAR, M.; CULHACI, N. y cols.: "Relapse of brucellosis simulating testis tumor". Int. J. Urol., 11: 683, 2004.

*11. AKINCI, E.; BODUR, H.; ERBAY, C.C. y cols.: "Brucella abortus epididymo-orchitis relapsing in the opposite testis 3 months after antibiotic therapy and development of aspermia”. Int. J. Infect. Dis., 7: 290, 2003. 